\title{
ALTERNATIVAS POLÍTICAS E PEDAGÓGICAS DA PRODUÇÃO DE SABÃO ARTESANAL: UM DIÁLOGO COM A EDUCAÇÃO AMBIENTAL
}

\author{
Venâncio Alves Amaral ${ }^{1}$ \\ Marco Vinícius Chaud² \\ Marcos Antonio dos Santos Reigota ${ }^{3}$
}

Resumo: $O$ estudo foi desenvolvido com três objetivos integrados: (i) adquirir referencial teórico sobre a temática do óleo residual de cozinha e os impactos causados pelo descarte inadequado; (ii) aplicar o método etnográfico para obtenção de dados sobre a cultura da fabricação de sabão artesanal no Munícipio de Paramirim/BA; (iii) realizar análise laboratorial da qualidade do sabão produzido. Para apreensão dos dados foi realizado: (i) estudo bibliográfico; (ii) método etnográfico (Martyn Hammersley e Paul Atkinson, 2007); (iii) análise sensorial, testes de densidade, teor de umidade, propriedade de consistência e potencial hidrogeniônico $(\mathrm{pH})$. O método etnográfico foi eficiente para apreensão dos dados no contexto social estudado. A análise laboratorial constatou que uma das amostras possui $\mathrm{pH}$ básico muito elevado, podendo causar riscos à saúde dos fabricantes e usuários do sabão. Os dados empíricos fundamentam uma proposta de Educação Ambiental com as mulheres na Bahia.

Palavras-chave: Óleo Residual de Cozinha; Descarte; Sabão Artesanal; Etnografia; Educação Ambiental.

1 Universidade de Sorocaba - UNISO. E-mail: venancio mt@hotmail.com

2 Universidade de Sorocaba - UNISO. E-mail: marco.chaud@prof.uniso.br

${ }^{3}$ Universidade de Sorocaba - UNISO. E-mail: marcos.reigota@prof.uniso.br 


\title{
Introdução
}

Diante do crescimento populacional apresentado nos últimos trinta anos, houve também um aumento na geração de resíduos sólidos urbanos (RSUs), usualmente denominado como lixo urbano (SANTOS FILHO et al., 2017). De acordo com a Associação Brasileira de Normas Técnicas - ABNT (2004) os resíduos sólidos são definidos como:

\begin{abstract}
Resíduos nos estados sólido e semi-sólido, que resultam de atividades de origem industrial, doméstica, hospitalar, comercial, agrícola, de serviços e de varrição. Ficam incluídos nesta definição os lodos provenientes de sistemas de tratamento de água, aqueles gerados em equipamentos e instalações de controle de poluição, bem como determinados líquidos cujas particularidades tornem inviável 0 seu lançamento na rede pública de esgotos ou corpos de água, ou exijam para isso soluções técnica e economicamente inviáveis em face à melhor tecnologia disponível (ABNT, 2004, p. 1).
\end{abstract}

Os RSUs gerados pela sociedade em suas diversas atividades resultam em riscos à saúde pública (transmissão de doenças provocadas por meio de vetores, que encontram no lixo condições adequadas para sua proliferação), provocam problemas ambientais (contaminando ar, água e solo), devido à disposição final inadequada do lixo urbano, causando consequências que afetam o contexto social, econômico e administrativo (SIQUEIRA; MORAES, 2009).

Dentro desse contexto, uma perspectiva inversa pode ser observada, isso, por que alguns RSUs possuem um grande potencial para a reciclagem, podendo se transformar em fonte de renda, por exemplo, a matéria orgânica (reciclada por meio de compostagem), e além dessa, também há outros resíduos, tais como papel, papelão, metais, plásticos e vidros, que possuem mercado comprador (SCHOTT FILHO et al., 2017). No entanto, dentre os resíduos que ainda possui relativo descuido perante a sociedade, está o óleo residual de cozinha (ORC) proveniente da fritura dos alimentos (OLIVEIRA et al., 2016).

Uma revisão da literatura realizada por Silva, Braz e Pinheiro (2017) sobre o uso e descarte do ORC mostrou que este material se encontra entre os resíduos que não possuem método definido para o seu gerenciamento, manuseio, coleta, tratamento e descarte. Na caracterização dos RSUs o óleo as vezes é classificado como matéria orgânica, em outros, como óleos. Por apresentar potenciais riscos à saúde das pessoas e ao meio ambiente, dessa forma, as atividades do seu gerenciamento carecem de organização e controle do descarte.

Embora ainda não haja um gerenciamento definido, pesquisas apontam métodos de descarte mais adequados para o ORC, podendo servir de matériaprima para a fabricação de sabão, detergente, ração animal, glicerina, lubrificante para engrenagens, composição de tintas e biodiesel (PITTA JUNIOR et al., 2009; FREITAS; BARATA; NETO 2010).

Revbea, São Paulo, V. 14, № 3: 50-74, 2019.

revista brasileira educação ambiental 
Em pesquisa realizada por Do Monte et al. (2015) por meio de coleta de dados em amostragem, 340 pessoas responderam a um questionário no qual havia a seguinte pergunta: Você conhece alguma forma de reutilizar ou reciclar o óleo de cozinha utilizado? A) Sim (Qual) ou B) Não. Obtendo como resultados: $46,7 \%$ do total de pessoas não lembram ou não conhecem alguma forma de reciclar ou reutilizar este resíduo. Em contrapartida, 53,3\% responderam que sim, no entanto, foram citadas apenas duas maneiras de reutilização do óleo de cozinha usado, sendo para a fabricação de sabão $(42,6 \%)$ e para a refritura de alimentos (10,6\%) (DO MONTE et al., 2015).

Neste sentido, se faz necessário a busca por uma sensibilização da população quanto as problemáticas causadas pelo ORC. Uma estratégia possível é a aplicação de conceitos de Educação Ambiental como educação política:

A Educação Ambiental como educação política é por princípio: questionadora das certezas absolutas e dogmáticas; é criativa, pois busca desenvolver metodologias e temáticas que possibilitem descobertas e vivências, é inovadora quando relaciona os conteúdos e as temáticas ambientais com a vida cotidiana e estimula o diálogo de conhecimento científicos, étnicos e populares e diferentes manifestações artísticas; e crítica muito crítica, em relação aos discursos e às práticas que desconsideram a capacidade de discernimento e de intervenção das pessoas e dos grupos independentes e distantes dos dogmas políticos, religiosos, culturais e sociais e da falta de ética (REIGOTA, 2009, p. 15).

Em relação a evolução dos conceitos de Educação Ambiental, Mota Junior (2009) aborda sobre a ligação direta estabelecida entre a Educação Ambiental e o meio ambiente, no entanto, pontuando a maneira como essa ligação era reduzida exclusivamente a aspectos naturais, não permitindo as interdependências e contribuições das ciências sociais e outras ciências para compreensão e melhora do ambiente humano.

Essa evolução dos conceitos, mostra a Educação Ambiental com característica inter/transdisciplinar, e além disso, podemos observar a ação política descrita por Mota Junior (2009):

Portanto, a Educação Ambiental é um processo que consiste em propiciar às pessoas uma compreensão crítica e global do ambiente. Compreensão esta que possibilita ao sujeito elucidar valores e desenvolver atitudes que lhe permita adotar uma posição consciente e participativa a respeito das questões relacionadas com a conservação, bem como a apresentar adequada utilização dos recursos naturais para a melhoria da qualidade de vida e a eliminação da pobreza extrema e consumismo desenfreado (MOTA JUNIOR, 2009, p. 2015). 
Desse modo, acreditamos que a Educação Ambiental como educação política estimula vários questionamentos, inclusive 0 diálogo entre 0 conhecimento popular e o conhecimento científico. O conhecimento popular pode ser definido como informações que são acumuladas ao longo do tempo por uma determinada comunidade, em relação as suas práticas, valores, culturas, vivências e experiências, no entanto, estes conhecimentos não são inalteráveis, nem inabaláveis, pois são gerados, modificados e reformulados pela própria comunidade (SANTOS; NAGASHIMA, 2017). Já o conhecimento científico é um constante vaivém de hipóteses e expectativas lógicas, do que pode "ser" e o que "é", uma permanente discussão, argumentação e contra argumentação entre teoria, observações e experimentações realizadas (PRAIA; CACHAPUZ; GIL-PÉREZ, 2002).

Portanto esse estudo foi desenvolvido utilizando os conceitos de Educação Ambiental, abordando os impactos ambientais causados pelo descarte inadequado do ORC e evidenciando umas das possíveis formas de descarte adequado. $O$ descarte escolhido foi a reutilização como matéria-prima para a fabricação de sabão artesanal, apreendendo informações por meio do método etnográfico, evidenciando o conhecimento popular e posterior integração por meio do conhecimento científico.

\section{Método}

\section{Estudo Bibliográfico}

O estudo bibliográfico foi realizado tendo como base os artigos científicos disponíveis por meio do portal de periódicos da CAPES e na plataforma do Google Acadêmico, publicados no Brasil a partir de 2008 a 2018, com os descritores: óleo residual de cozinha, descarte, impacto ambiental e Educação Ambiental.

\section{Etnografia}

O método etnográfico foi aplicado tendo como base os conceitos descritos no livro "Ethnography: Principles in Practice" dos autores Martyn Hammersley e Paul Atkinson (2007), a técnica utilizada para apreensão de dados foi o "Diário de campo". Essa técnica permite o distanciamento indispensável na pesquisa e a posterior análise dos dados apreendidos. A etnografia foi realizada no contexto social das mulheres fabricantes do sabão artesanal no Município de Paramirim/BA, entre os meses de Junho e Julho de 2018. Por ser uma pesquisa etnográfica, teve por princípio a abordagem qualitativa e interpretativa da análise dos dados, pois o ponto central foram as práticas e eventos cotidianos em torno do contexto observado. 


\section{Avaliação da qualidade do sabão artesanal}

Os sabões utilizados para as análises laboratoriais foram produzidos de maneira artesanal por fabricantes residentes no Município de Paramirim/BA. As amostras (A1, A2 e A3) foram produzidas por técnica similar, seguindo "receita popular". As matérias-primas e as quantidades utilizadas são descritas na Tabela 1.

Tabela 1: Composição utilizada na fabricação dos sabões artesanais.

\begin{tabular}{ccccccc}
\hline Amostras & $\begin{array}{c}\text { Óleo residual } \\
\text { de cozinha } \\
(\mathbf{L})\end{array}$ & $\begin{array}{c}\text { Gordura } \\
\text { animal } \\
(\mathbf{L})\end{array}$ & $\begin{array}{c}\text { Água } \\
\text { potável } \\
(\mathbf{L})\end{array}$ & $\begin{array}{c}\text { Álcool } \\
\text { etílico } \\
(\mathbf{L})\end{array}$ & $\begin{array}{c}\text { Soda } \\
\text { cáustica } \\
(\mathrm{Kg})\end{array}$ & $\begin{array}{c}\text { Detergente } \\
\text { comercial } \\
(\mathbf{L})\end{array}$ \\
\hline A1 & 3 & 2 & 3 & 0,5 & 1 & 0,5 \\
A2 & 4 & - & 3 & 3 & 1 & 0,5 \\
A3 & 4 & 0,5 & 3 & 3 & 1 & 0,5 \\
\hline
\end{tabular}

Fonte: De autoria própria.

A partir da aquisição do sabão artesanal, cada amostra foi caracterizada usando padrão sensorial (tato, visão e olfato), analisando respectivamente o aspecto físico, cor e odor. As amostras também foram analisadas quanto a densidade, propriedade de consistência e propriedade físico-química (teor de umidade e potencial hidrogeniônico - pH).

\section{Análise sensorial}

A análise sensorial permite avaliar as características qualitativas da amostra, identificadas pelos órgãos do sentido. Podendo verificar alterações como coloração, odores, separação de fases, precipitação e turvação no produto.

\section{Densidade}

As densidades das amostras foram calculadas utilizando a Equação (1):

$$
d=\frac{m}{V}
$$

Onde $d$ é a densidade $\left(\mathrm{g} / \mathrm{cm}^{3}\right), m$ é a massa $(\mathrm{g})$, e $v$ é o volume $\left(\mathrm{cm}^{3}\right)$.

Para aferição de massa a amostra foi pesada em balança analítica (Tecnal, B-TEC-210A. Piracicaba, Brasil), o volume foi determinado pelas dimensões geométricas de cada amostra, as medidas obtidas foram aplicadas na Equação (2):

$$
V=a \times b \times c
$$

Onde $v$ é o volume $\left(\mathrm{cm}^{3}\right)$, $a$ é o comprimento, $b$ é a largura, e $c$ é a altura de cada amostra de sabão. As medidas foram feitas em triplicata por amostra $(\mathrm{n}=3)$. 


\section{Teor de umidade}

Para o teste, cada amostra foi cortada nas dimensões $1,80 \times 1,50 \times 0,50$ $\mathrm{cm}$ e submetida a secagem utilizando balança determinadora de umidade (Shimadzu - MOC-63U. Kyoto, Japão). A amostra foi colocada em cadinho de alumínio e expostas a radiação infravermelha até massa constante, o teste foi realizada nos tempos 10,20 e 30 dias. As condições de secagem do equipamento foram mantidas no modo "slow", $60{ }^{\circ} \mathrm{C}$, variação de massa de $0,05 \%$ e precisão de $0,001 \mathrm{~g}$. $(\mathrm{n}=3)$.

\section{Propriedade de consistência}

Antes do teste de consistência o analisador de textura (Stable Micro Systems, modelo TA-XT Plus, UK) foi previamente calibrado com uma célula de carga de $5 \mathrm{~kg}$. Para a realização do teste a amostra foi cortada nas dimensões de $3 \times 2 \times 1,50 \mathrm{~cm}$. Uma sonda analítica SMS-P5S foi comprimida sobre a superfície de cada amostra com uma força de $0,049 \mathrm{~N}$. A velocidade do teste foi determinada a uma taxa de $1 \mathrm{~mm} / \mathrm{s}^{-1}$ e a profundidade de penetração da sonda foi fixada para $5 \mathrm{~mm}$. A determinação da consistência da amostra foi realizada em modo de compressão e analisada por relação força $(\mathrm{N}) \times$ tempo (s), os dados foram registrados por meio do software (Exponente Texture Analysys). ( $n=3)$.

\section{Potencial hidrogeniônico $(p H)$}

A medida do $\mathrm{pH}$ foi realizada com peagômetro digital (Tecnal, TE-5. Piracicaba, Brasil) previamente calibrado na faixa de $\mathrm{pH}$ entre $4-7$ e 7 - 14, na temperatura de $25 \pm 2 \stackrel{\circ}{ } \mathrm{C}$. O teste foi realizado nos tempos 10,20 e 30 dias. Cada amostra $(1 \mathrm{~g})$ foi dispersa em $10 \mathrm{~mL}$ de água purificada e neutralizada $(\mathrm{pH}$ $6,9-7,0) .(n=3)$.

\section{Tratamento estatístico}

O tratamento estatístico dos dados obtidos foi realizado por análise de variância unidirecional (ANOVA) seguida pelo teste post hoc de Tukey utilizado para analisar estatisticamente as médias obtidas nos diferentes ensaios, e determinada com intervalo de confiança de $95 \%(p<0,05)$.

\section{Resultados e discussão}

\section{Óleo residual de cozinha e os impactos ambientais}

Segundo dados do Instituto Brasileiro de Geografia e Estatística - IBGE, o município de Paramirim possui uma população de 21.001 habitantes (censo populacional 2010) e está localizado na região centro sul do Brasil, sua área territorial $\left(1.170,133 \mathrm{~km}^{2}\right)$ é totalmente abrangida pelo polígono das secas. Está situada na parte sudoeste do estado da Bahia, microrregião de Livramento do Brumado e faz parte da bacia hidrográfica do Rio São Francisco, sendo o rio 
Paramirim um dos maiores e mais importantes afluentes da margem direita do São Francisco (BRASIL, 2019a).

O município de Paramirim apresenta uma realidade ainda encontrada em pequenos municípios brasileiros, onde o sistema de saneamento básico é precário ou mesmo inexistente, tornando um potencial gerador de resíduos poluentes, devido à falta de tratamento adequado.

Em outra realidade, onde há saneamento básico adequado e o ORC é descartado de maneira inadequada, despejado na pia, ralos ou até mesmo em vasos sanitários, como resultado, o óleo é direcionado à Estação de Tratamento de Esgoto (ETE), chegando de forma intacta, uma vez que dificilmente se decompõe. Por conta disso, é necessário um empenho maior da ETE para o tratamento eficiente do efluente sanitário, e assim, a água possa ser direcionada novamente para os rios, lagos e represas (NEVES; GUEDES; SANTOS, 2010).

Com a persistência do descarte inadequado, o óleo se aloja internamente nas tubulações formando uma camada gordurosa que adere todo tipo de resíduo sólido, criando uma massa que aos poucos obstrói os canos, acarretando no entupimento das tubulações e no refluxo do efluente (MORGAN-MARTINS et al., 2016). Em alguns casos, para a desobstrução das tubulações domésticas, os moradores utilizam objetos pontiagudos, como fios e arames, podendo danificar a estrutura física dos canos. Quando esta abordagem falha, é comum recorrer à utilização de produtos químicos, por exemplo, o hidróxido de sódio (soda cáustica/ $\mathrm{NaOH})$ e o ácido clorídrico $(\mathrm{HCl})$, que são tóxicos e podem causar corrosão nas tubulações, acarretando no rompimento da rede de esgoto, e desta forma, desencadeando efeitos negativos ao meio ambiente e também financeiros, pois esse tipo de intervenção inadequada pode levar à troca parcial ou total das tubulações (MATTA; NETO, 2016).

Para as ETEs, isso toma proporções ainda maiores, exigindo um tratamento mais eficiente dos efluentes sanitários contendo o ORC, existindo a necessidade de manutenção precoce da rede de tubulações, encarecendo em até $45 \%$ os custos operacionais (FILHO et al., 2013).

No entanto, quando não há saneamento básico no município, o ORC não passa por um tratamento prévio do esgoto e por vezes, é direcionado para os mananciais hídricos próximos. Sendo que apenas um litro do óleo é capaz de contaminar até um milhão de litros de água (OLIVEIRA; DUTRA, 2016). Quando esse resíduo chega aos mananciais, eleva as concentrações de ácidos graxos insolúveis, comprometendo a qualidade da água, ocasionando alterações pontuais no pH (TESCAROLLO et al., 2015).

Em função da imiscibilidade do óleo e por possuir uma densidade menor em comparação a água, existe a possibilidade de aglutinação e formação de uma película oleosa na superfície dos mananciais hídricos, dificultando as trocas gasosas com a atmosfera, gerando uma diminuição das concentrações de oxigênio no ambiente aquático (MORGAN-MARTINS et al., 2016). Além 
disso, essa película oleosa dificulta a entrada da luz solar, um componente essencial para o processo de fotossíntese (LISBOA et al., 2016) e sob a incidência da radiação causa o aumento da temperatura, podendo alcançar o patamar de $60{ }^{\circ} \mathrm{C}$, essa intensificação modifica a propriedade termofísica do ORC, causando a diminuição da viscosidade, liberando pequenos resíduos sólidos para o ambiente. A somatória desses efeitos criam condições favoráveis para causar a morte de espécies animais, vegetais e seres microscópicos aeróbicos (TESCAROLLO et al., 2015).

Outro aspecto relevante é o fato de que, uma vez em contato com a água, existem microrganismos capazes de decompor o ORC, por meio do processo de biotransformação, onde combinações de reações bioquímicas transformam a estrutura molecular do óleo, resultando como subproduto o gás metano $\left(\mathrm{CH}_{4}\right)$, um dos gases que compõem o efeito estufa, contribuindo para o aumento na temperatura do planeta (BERTÊ; FANTINEL; FERNANDES, 2014), isso ocorre devido a sua geometria molecular tetraédrica, que retém vinte vezes mais energia que o dióxido de carbono $\left(\mathrm{CO}_{2}\right)$ que possui geometria molecular linear (AZEVEDO et al., 2009).

Em contraponto, quando o ORC é descartado de maneira inadequada e lançado diretamente no solo, como consequência, o óleo vai se difundindo e disputando os espaços, que correspondem aos interstícios (espaços vazios) entre as partículas do solo, formado pelos micro e macroporos, que normalmente seriam ocupados pela água e/ou pelo ar (MILLIOLI et al., 2008). Essa ocupação impede a infiltração da água e do ar, causando a impermeabilidade do solo, debilitando a capacidade de drenagem, causando a erosão e destruição da vegetação local, afetando a renovação dos lençóis freáticos e favorecendo a ocorrência de enchentes (FERREIRA; SANTOS, 2014)

A incidência da radiação solar sob o ORC no solo também causa o aumento da temperatura $\left(60^{\circ} \mathrm{C}\right)$, que proporcionalmente altera a propriedade termofísica, diminuindo a sua viscosidade, deixando o óleo mais fluído. Em estudo realizado por Brock et al. (2008) foram investigados a influência da variação de temperatura entre $20-70^{\circ} \mathrm{C}$ no comportamento da viscosidade de seis tipos de óleos vegetais (soja, milho, arroz, algodão, oliva e canola), constando diminuição acentuada na viscosidade de todos os óleos vegetais à medida que a temperatura foi aumentada. Esse resultado indica que proporcionalmente ao aumento na temperatura haverá o aumento na fluidez do ORC, causando maior infiltração desse resíduo por meio dos interstícios presentes no solo.

Essa ocupação ocasiona outro problema, por se tratar de um composto orgânico, os microrganismos que compõem a microbiota do solo atuam na sua decomposição, através do processo de biotransformação, resultando como subproduto o gás metano $\left(\mathrm{CH}_{4}\right)$, intensificando o efeito estufa e contribuindo para o aumento na temperatura (OLIVEIRA; DUTRA, 2016). 
Outra forma de descarte inadequado que ocorre com o ORC é a disposição no lixo domiciliar, cujo destino provável são os aterros sanitários (TOMASI et al., 2014). O procedimento típico de um aterro é a compactação do lixo, para a realização segura desse processo, a área deve possuir um sistema de geomembranas (mantas de Polietileno de Alta Densidade - PEAD, utilizadas para o recobrimento de uma área no solo impedindo o vazamento ou infiltração de efluentes). Sem esse sistema, ocorre a infiltração do óleo nos taludes junto a outros resíduos oriundos do lixo, causando a contaminação do solo, podendo alcançar o lençol freático, além disso, diminuindo a vida útil do aterro sanitário (WILDNER; HILLIG, 2012).

Dentro do contexto apresentado no estudo, ficou nítido a necessidade de uma abordagem que busque sensibilizar os cidadãos, evidenciando os possíveis descartes adequados para o ORC. Visto que esse mesmo resíduo que causa impactos ambientais pode ser utilizado como matéria-prima para a fabricação de sabão (líquido ou em barra), detergentes, ração animal, glicerina, lubrificante para engrenagens, composição de tintas e produção de biodiesel. Entre esses possíveis descartes, a aplicação para a fabricação de sabão em barra artesanal é uma prática usual pelas mulheres residentes no Município de Paramirim/BA, dessa forma esse contexto social foi estudado por meio de método etnográfico.

\section{Etnografia}

Para fundamentar a discussão do estudo etnográfico, foi utilizado como base o referencial teórico-argumentativo obtido por meio do estudo bibliográfico (acervo de 75 publicações), a princípio esse método teve o objetivo de adquirir um referencial, abordando os impactos ambientais devido ao descarte inadequado do ORC. Paralelamente, o método contribuiu para evidenciar outros eixos estruturais da pesquisa, aplicadas a prática de sabão artesanal, evidenciando conceitos de empreendedorismo social, sustentabilidade, logística reversa, educação CTSA (Ciência, Tecnologia, Sociedade e Ambiente), ensino de química e de ciências. Além disso, evidenciou estudos que demostram similaridades com as práticas realizadas pelas mulheres fabricantes do sabão artesanal. análise:

No referencial do acervo obtido, foram selecionados 4 artigos para

- Empreendedorismo social e sustentabilidade: Um estudo de caso sobre o projeto "Mulheres em ação jogando limpo com a natureza" do IFNMG. (Estado - Minas Gerais) (NEVES; GUEDES; SANTOS, 2010).

- Abordagem CTSA - Prática pedagógica no ensino de ciências a partir da produção de sabão caseiro. (Estado - Espírito Santo) (TEIXEIRA et al., 2015).

- Conhecimento popular e a educação CTS em oficinas de sabão caseiro. (Estado - Goiás) (SILVA; SANTOS, 2016).

- Saber popular e o conhecimento científico: Relato de experiência envolvendo a fabricação de sabão caseiro. (Estado - Paraná) (SANTOS; NAGASHIMA, 2017). 
Após a seleção, os artigos foram analisados e utilizados como referência para discussão dos dados obtidos.

Enquanto método de pesquisa, a etnografia é originária na antropologia, sendo aplicada na tentativa de compreender as percepções e conceitos de um determinado grupo social em relação a um acontecimento, comportamento ou fenômeno social e cultural (REIS; LUNARDI-MENDES, 2018).

Dessa forma, a aplicação da Educação Ambiental de maneira inter/transdisciplinar em acordo com 0 método etnográfico se faz tão importante, pois a visão etnográfica do pesquisador/participante em contato com o universo dos participantes, permiti compartilhar de seus horizontes, não para permanecer lá ou mesmo para atestar a lógica de sua visão de mundo, porém, para observá-los até onde seja possível, estabelecendo uma relação de troca (MAGNANI, 2009).

O método de pesquisa consiste em um instrumento de investigação provido de diferentes técnicas: entrevistas abertas, levantamento de dados locais (estatísticas de órgão públicos, mapas, documentos e publicações sobre o tema) e utilização do diário de campo ou diário etnográfico (ADOMILLI; TEMPASS; LOPES, 2017).

O pesquisador/participante adentrou no contexto social das mulheres, observando de perto as práticas, assimilando e transcrevendo em diário de campo, utilizamos os recortes do diário para reconstrução da trajetória e discussão da pesquisa após imersão no cotidiano estudado. Em relação a essa vertente do método etnográfico Weber (2009) comenta:

É o diário que permite o distanciamento indispensável na pesquisa de campo, e que permitirá mais tarde a análise do desenvolvimento da pesquisa. É também o diário que mostra, a cada etapa da reflexão, os laços entre as diversas hipóteses levantadas pelo pesquisador e o momento da pesquisa em que essas hipóteses foram reformuladas (WEBER, 2009).

Desse modo, o diário de campo proporciona um reencontro com o grupo pesquisado e o cotidiano vivenciado. No primeiro contato com as mulheres fabricantes do sabão artesanal foi possível conhecer as principais matériasprimas utilizadas na fabricação:

Os materiais necessários para preparar o sabão artesanal foram: uma bacia grande de plástico, uma lata de metal, um bastão de madeira, água, óleo de cozinha usado, gordura animal (sebo bovino) e soda cáustica. Esses são materiais básicos para a fabricação do sabão, no entanto, na receita foi utilizado também o álcool etílico (combustível) e detergente líquido (recorte do diário de campo). 
Por meio do acompanhamento da fabricação de sabão, observamos que haviam preferências na utilização de matérias-primas por algumas das mulheres, ocorrendo uma divergência, uma delas não gostava de adicionar gordura animal (sebo bovino) na mistura, explicando que deixava o sabão com odor mais forte. Outra já optava por acrescentar, explicando que melhora o ponto de corte do sabão. Essa divergência observada na proporção também foi relatada no estudo realizado por Silva e Santos (2016) e por Teixeira et al. (2015).

Essa diversidade de proporções e matérias-primas utilizadas podem causar problemas, acometendo ao excesso ou falta de algum componente na mistura do sabão, ocasionando a acidificação ou alcalinização, comprometendo dessa forma 0 produto final. Nesse sentido, se faz necessário a análise laboratorial para verificação da qualidade do produto, esclarecendo os fabricantes sobre as boas práticas na fabricação, sensibilizando em questões de segurança, pois a soda cáustica é um produto que pode causar intoxicação, irritação e até queimaduras na pele, requerendo cuidados em seu manuseio.

Essa preocupação foi evidenciada no estudo de campo:

Confesso que fiquei preocupado, muito mesmo. Porque a água quente serviria para solubilizar a soda cáustica, um produto químico que deve ser manuseado com bastante cuidado e que em contato com a água, gera vapor, sendo irritante para os olhos e as vias nasais. Observei que certos cuidados eram tomados, como por exemplo, a utilização de camisa manga longa, porém, não havia proteção para as pernas e os pés, estes ficavam à mostra.

Quando a água aqueceu e o sebo estava derretido, voltamos para o quintal, a soda cáustica foi colocada na bacia de plástico, então a água quente seria adicionada, mas antes disso só escutei o aviso da senhora "sai de perto menino, que esse negócio é perigoso!". Não pensei duas vezes, saí o mais rápido possível e fiquei observando a agilidade da senhora ao colocar a água, tendo um pano cobrindo boa parte do rosto, principalmente as vias nasais (recorte do diário de campo).

Diante desse fato, ficou evidente a falta do uso de equipamentos de proteção individual - EPIs para minimizar o risco de acidentes. É recomendado a utilização de luvas, óculos de segurança, jaleco ou avental (desde que seja manga longa), sapato fechado, e realizar o procedimento sempre em local aberto e arejado (SILVA; SANTOS, 2016; SANTOS; NAGASHIMA, 2017).

No entanto, após o susto perante o risco em que as fabricantes estavam se colocando e devido essa preocupação, uma delas relatou: 
Certa vez um senhor foi até um estabelecimento para comprar a soda cáustica para fabricar o sabão, antigamente os estabelecimentos não vendia em embalagens pequenas e próprias para o transporte. Eram comprados em grandes sacos, a soda não era em escamas, e acabava ficando empedrada, havendo a necessidade de ser quebradas.

Olha o que aconteceu, o senhor foi comprar a soda e quando estava quebrando as pedras, não reparou que um grão havia caído próximo a orelha e ao chegar em casa sentiu a sensação de ardor, coçou e não parou de arder, mas quando foi olhar, a soda tinha corroído e feito uma ferida em sua orelha (relato de uma das fabricantes).

A partir desse relato podemos notar que havia informações em relação aos riscos na utilização da soda cáustica e essa consciência foi expressa no momento da prática de produção do sabão. Esse saber popular poderia ser a base para adentrar novas informações sobre boas práticas e questões de segurança no processo de fabricação. Após esse relato seguimos com os procedimentos da prática:

Depois de todo o trabalho de produção, a massa obtida ficou em repouso de um dia para o outro, só após este tempo que foi efetuado o corte das barras, porém, para que pudesse utilizar o sabão, houve a necessidade de aguardar entorno de 15 dias, tempo para curtir a soda (recorte do diário de campo).

Essa mesma orientação sobre o tempo de cura da soda foi observada em relato apresentado por Teixeira et al. (2015) advertindo que o sabão só poderia ser utilizado após um período de 15 a 20 dias, tempo necessário para que a soda cáustica possa reagir por completo com os componentes utilizados na fabricação do sabão, finalizando a reação química do produto.

Com o sabão artesanal pronto e o tempo de cura realizado, parte da produção foi destinada para os familiares (uso próprio), a outra parte, foi vendida no próprio bairro e/ou comercializados na feira livre municipal. Nessa perspectiva de produção, o sabão artesanal foi inserido como fator econômico para as mulheres, auxiliando no acréscimo da renda ou para minimizar os gastos com a compra de outros produtos de limpeza.

Depois de finalizarmos a prática, uma das fabricantes convidou para tomar um café. Durante o cafezinho começou a contar sobre as vivências e de como era preparado o sabão no tempo de sua juventude, relatou também sobre os engenhos onde eram produzidas as rapaduras: 
Neste tempo, já havia todo um sistema para aproveitar ao máximo os recursos utilizados na produção de rapadura, bem antes da moagem da cana de açúcar, preparavam a quina decuadra, uma espécie de coador feito com ganchos de madeira e varinhas de marva dobradas, dentro deste recipiente era adicionado cinzas de árvores, as mais utilizadas eram a quixabeira (Sideroxylon obtusifolium), o juazeiro (Ziziphus joazeiro) e o angico branco (Anadenanthera colubrina). Os troncos das árvores eram queimados e as cinzas recolhidas e depositadas na quina decuadra. Quando ocorria de ficar espaços muito largos na quina, era necessário ocupá-los com folhas de Gravatá (Bromelia antiacantha), para que as cinzas não pudessem passar, com a quina pronta e com as cinzas depositadas, era então adicionado água, que serviria para lavar as cinzas lentamente. Embaixo da quina era colocado uma cuia ou cabaça para aparar o líquido escoado, esse processo era repetido várias vezes, e com o passar do tempo era adicionado mais cinzas.

Para mensurar o ponto da quina, era necessário provar, molhar a ponta do dedo e colocar na ponta da língua, se adormecer é por que está no ponto. Depois de todo esse processo e a quina pronta, os trabalhos no engenho começavam, pois, esse líquido era utilizado para curtir a garapa da cana de açúcar, tirando as impurezas até chegar ao ponto de cura da rapadura.

No entanto, mesmo com a rapadura pronta, a quina restante não era jogada fora, era reaproveitada, repassando o processo mais vezes e se necessário utilizando as cinzas úmidas para a produção de sabão, o chamado de sabão decuadra. Esse sabão também era produzido utilizando os frutos da árvore Nogueira (Carya illinoinensis).

Com o decorrer do tempo, a produção de sabão foi se diversificando, principalmente com a chegada da soda cáustica. Com a sua utilização, começaram a fabricar o chamado sabão de bolo, que era preparado utilizando as vísceras de porcos, bois ou bodes. A senhora acrescentou em sua fala que o melhor era o sabão feito com as vísceras de bode, por que não apresentavam cheiro forte e ficavam mais alvinhos, porém, com as vísceras de porcos ficavam com o cheiro forte e escuros, no entanto, esse material era o mais fácil de adquirir (recorte do diário de campo).

Diante desse recorte do diário de campo, ficou evidente a força cultural, social, político e também o fator econômico exercido pela fabricação de sabão artesanal, uma herança dos tempos de juventude em que a família produzia para uso próprio, aproveitando ao máximo os recursos advindos de outras produções. Evidenciando uma dinâmica temporal do conhecimento popular nos processos de experimentação na produção do sabão, atualizados constantemente e validados ao longo das gerações.

Revbea, São Paulo, V. 14, № 3: 50-74, 2019. 
Analisando o fator econômico ligado as práticas realizadas pelas mulheres, e de acordo com o Programa das Nações Unidas para o Desenvolvimento - PNUD, calculamos o crescimento apresentado entre 0 ano 2000 e 2010 do Munícipio de Paramirim por meio dos dados mensurados no Índice de Desenvolvimento Humano (IDH). Os resultados mostram que o Munícipio apresentou uma taxa de crescimento de 23,25\%, passando de 0,499 para 0,615 . Nesse período, das três dimensões utilizadas para mensuração do $\mathrm{IDH}$, a que mais contribuiu para esse crescimento em termos absolutos foi a Educação, com $61,04 \%$, seguida pela longevidade, com $15,82 \%$, por fim, a renda foi a que menor contribuiu para o crescimento do IDH, com $0,17 \%$ (BRASIL, 2019b).

Deixando claro a importância do aproveitamento dos resíduos advindos de outras atividades para a geração de economia, evitando o descarte inadequado do ORC, contribuindo para a conservação do meio ambiente natureza e meio urbano.

\section{Avaliação da qualidade do sabão artesanal}

O ORC e a gordura animal (sebo) são substâncias hidrofóbicas compostas em sua maior parte por moléculas de ácidos e éster graxos. Os quais podem ser encontradas na forma livre ou ligadas a uma molécula de glicerol por meio de ligações tipo éster. $\mathrm{Na}$ forma ligada, seus derivados podem ser encontrados como monoacilglicerídeos, diacilglicerídeos e triacilglicerídeos (RAMALHO; SUAREZ, 2013). Os ésteres são responsáveis por fornecerem os ácidos graxos necessários para a obtenção do sabão artesanal pela formação de sais de ácidos graxos, como observado na reação de saponificação apresentada na Figura 1.

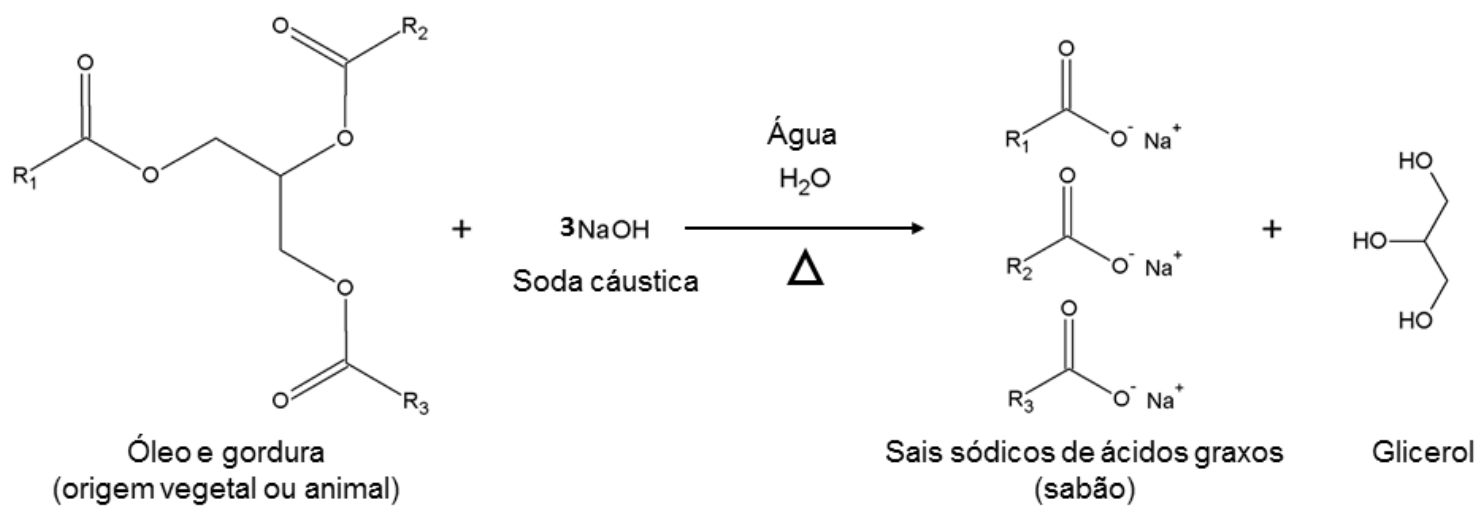

Figura 1: Representação da reação de saponificação para fabricação do sabão artesanal. As ramificações das cadeias carbônicas podem variar conforme o tipo de óleo ou gordura utilizadas, sendo representadas por R1, R2 e R3. Fonte: De autoria própria.

Analisando a reação de saponificação fica claro a relação da proporção para a formação dos sais sódicos de ácidos graxos, bem como as etapas do processo de reação, a água utilizada promove a hidrólise das ligações éster dos nomoacil, diacil e triacilglicerídeos presentes no óleo e gordura, deixando 
as moléculas de ácidos graxos livre para reagir com as moléculas de $\mathrm{NaOH}$. Já a adição do etanol na reação promove vantagens e desvantagens na obtenção dos sais, uma vez que a solubilidade do óleo/gordura se faz melhor em etanol do que em água, resultando na clarificação do sabão (RODRIGUES; COUTINHO; SILVA, 2010), além disso, a solução formada do etanol em água é exotérmica, processo pelo qual ocorre liberação de calor, consequentemente essa liberação aumenta a velocidade da reação de saponificação (SANTOS; NAGASHIMA, 2017). No entanto, a utilização do etanol ocasiona a redução na formação de espuma do sabão. Devido essa desvantagem os fabricantes adicionam no processo de fabricação detergente comercial como adjuvante para melhorar a qualidade do produto.

Se tratando da fabricação de sabão artesanal, isso provoca um sinal de alerta, pois as "receitas populares" estão em constante atualizações empíricas. Por sua vez, essas atualizações podem ser excessivas ou podem reduzir a quantidade de elementos essenciais no processo de fabricação resultando na reação incompleta de saponificação. Quando a quantidade de soda cáustica utilizada for muito superior à de ácido graxo ocorre a elevação da medida de $\mathrm{pH}$, podendo tornar o sabão impróprio para o uso. O inverso leva a uma acidificação do pH. Ambos são prejudiciais à saúde dos usuários e prejudiciais ao meio ambiente.

\section{Análise sensorial}

A análise sensorial fornece parâmetros que permitem avaliar os atributos das amostras, com objetivo de verificar alterações macroscópicas, possibilitando a caracterização do produto (LIMA et al., 2014). A Figura 2 mostra as imagens fotográficas das amostras adquiridas (A1, A2 e A3).

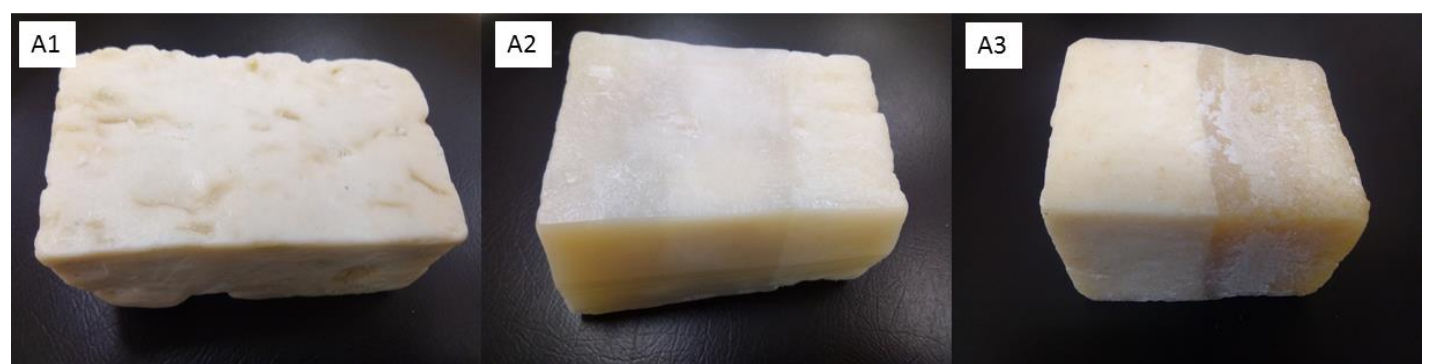

Figura 2: Imagens fotográficas das amostras de sabão artesanal adquiridas em Paramirim/BA. Fonte: De autoria própria.

Por meio da análise sensorial das amostras de sabão artesanal apresentadas na Figura 2 foi observado alterações pontuais em cada amostra. $\mathrm{Na}$ amostra $\mathrm{A} 1$ foi observado um sabão com aspecto homogêneo, superfície irregular, cor clara esbranquiçada, odor agradável, diferente do odor característico do ORC/gordura. Já a amostra A2 apresentou aspecto levemente separado, superfície regular, cor clara variando de esbranquiçado para amarelado, com odor agradável. Para a amostra A3 foi observado aspecto com separação de fases, superfície regular, cor clara esbranquiçado e amarelado, com odor agradável.

Revbea, São Paulo, V. 14, № 3: 50-74, 2019. 
$\mathrm{Na}$ descrição da receita dos sabões analisados, a homogeneização não segue um padrão estabelecido, sugerindo que esse processo seja realizado até que a mistura ganhe consistência. Esse fato, pode ter colaborado para a separação de fases observada nas amostras A2 e A3.

\section{Densidade}

A densidade é um parâmetro que está relacionado com o empacotamento das moléculas que compõem o material, por exemplo, quanto maior for o empacotamento mais denso é a material (CÉSAR; PAOLI; ANDRADE, 2004). Na Figura 3 são apresentados os resultados de densidade das amostras de sabão artesanal.

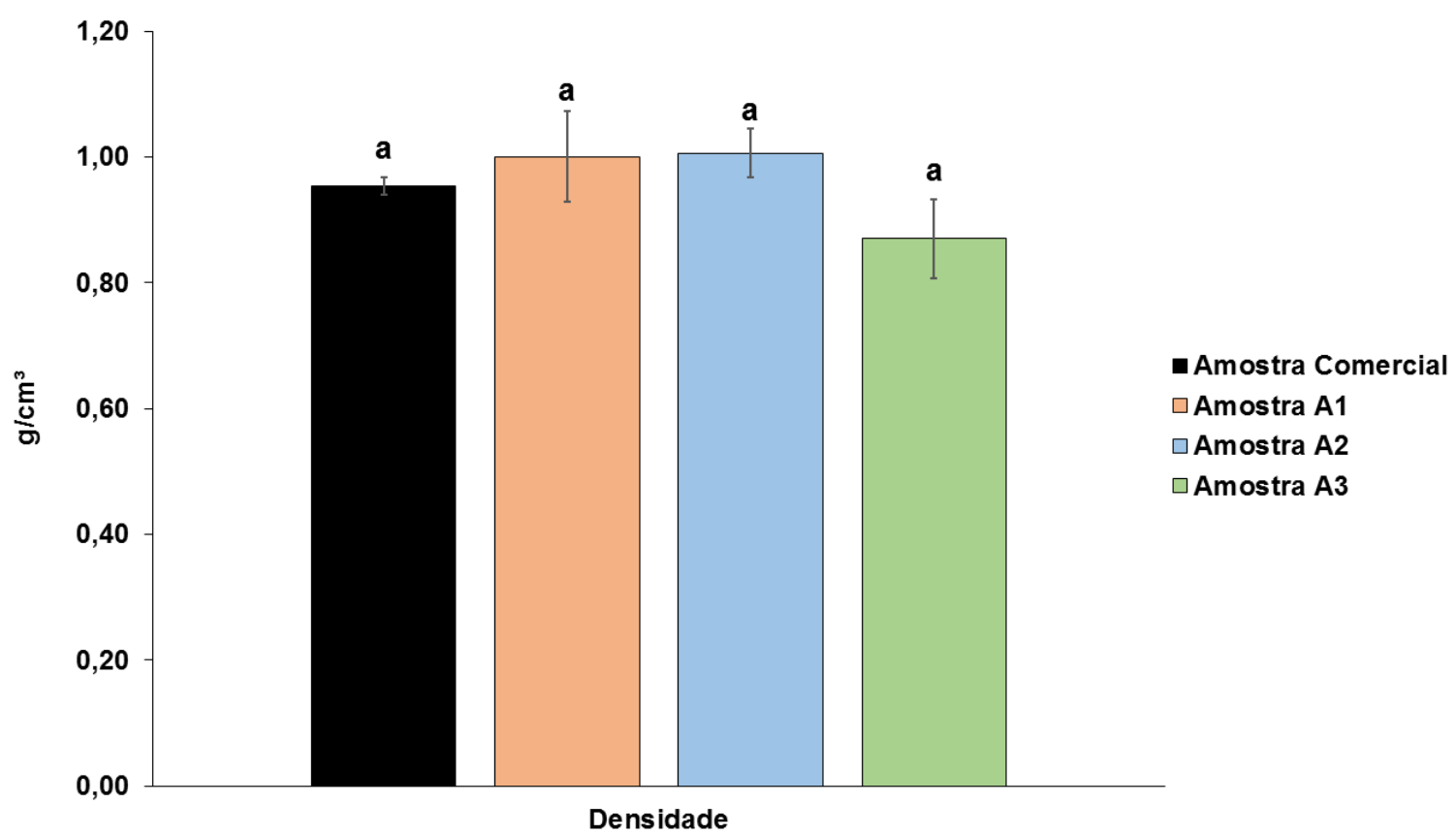

Figura 3: Densidade das amostras de sabão artesanal. Letras iguais indicam que não há diferença estatística significativa entre as médias dos valores $(p>0,05)(n=3)$.

Fonte: De autoria própria.

Apesar dos valores absolutos serem diferentes entre as amostras de sabão artesanal (A1 - 1,000 $\pm 0,072 \mathrm{~g} / \mathrm{cm}^{3}, A 2-1,006 \pm 0,039 \mathrm{~g} / \mathrm{cm}^{3}, A 3-$ $\left.0,870 \pm 0,063 \mathrm{~g} / \mathrm{cm}^{3}\right)$ e a amostra comercial $\left(0,954 \pm 0,015 \mathrm{~g} / \mathrm{cm}^{3}\right)$, a análise não apresentou diferença significativa entre as médias das amostras $(p>0,05)$. 


\section{Teor de umidade}

Os resultados de teor de umidade obtidos pelas amostras de sabão artesanal são apresentados na Tabela 2.

Tabela 2: Teor de umidade das amostras de sabão artesanal.

\begin{tabular}{cccc}
\hline Amostras & $\begin{array}{c}\text { Teor de umidade } \\
- \text { média (\%) }\end{array}$ & Desvio padrão & $\begin{array}{c}\text { Coeficiente de } \\
\text { variância (\%) }\end{array}$ \\
\hline A1 (10 dias) & $12,9^{\mathrm{c}}$ & 1,61 & 12,39 \\
A1 (20 dias) & $12,7^{\mathrm{c}}$ & 0,16 & 1,25 \\
A1 (30 dias) & $10,74^{\mathrm{c}}$ & 0,85 & 7,95 \\
A2 (10 dias) & $7,29^{\mathrm{b}}$ & 2,22 & 30,44 \\
A2 (20 dias) & $7,98^{\mathrm{b}}$ & 1,11 & 13,90 \\
A2 (30 dias) & $5,93^{\mathrm{b}}$ & 1,03 & 17,40 \\
A3 (10 dias) & $2,75^{\mathrm{a}}$ & 0,15 & 5,50 \\
A3 (20 dias) & $3,08^{\mathrm{a}}$ & 0,58 & 18,79 \\
A3 (30 dias) & $3,07^{\mathrm{a}}$ & 0,32 & 10,32 \\
\hline
\end{tabular}

Nota: Letras iguais indicam que não há diferença estatística significativa entre as médias dos valores $(p>0,05)(n=3)$. Fonte: De autoria própria.

Os resultados descritos na Tabela 2 mostram que apesar dos valores absolutos das amostras serem diferentes durante o período de tempo avaliado, a análise estatística intragrupo não apresentou diferença significativa $(p>0,05)$. No entanto, segundo a NBR 13903 - 1997, o critério para aceitação do resultado do teor de umidade é realizado por meio do cálculo do coeficiente de variância, de acordo com norma esse parâmetro tem que ser menor que 1,5\% (BRASIL, 1997). Ao comparamos os valores obtidos pelas amostras, podemos afirmar que, apenas a amostra A1 no tempo de 10 dias está em acordo com a norma.

\section{Propriedade de consistência}

No desenvolvimento do sabão artesanal é necessário levar em consideração as propriedades que determinam a aceitabilidade do produto final, dentre as propriedades analisadas, o aspecto físico e a consistência são fatores considerados importantes para garantir uma melhor aceitabilidade diante do futuro consumidor.

Em estudo realizado por Silva e Santos (2016) com a utilização de entrevistas com fabricantes do sabão artesanal, foram encontradas indicações sobre a preferência pelo uso em excesso da soda cáustica ( $\mathrm{pH}$ alcalino) para que o produto final ficasse mais consistente (Figura 4), constituindo um tipo de sabão que continha traços do reagente não consumido durante o processo de reação ácido-base, esse excesso reflete nas medidas de $\mathrm{pH}$. 


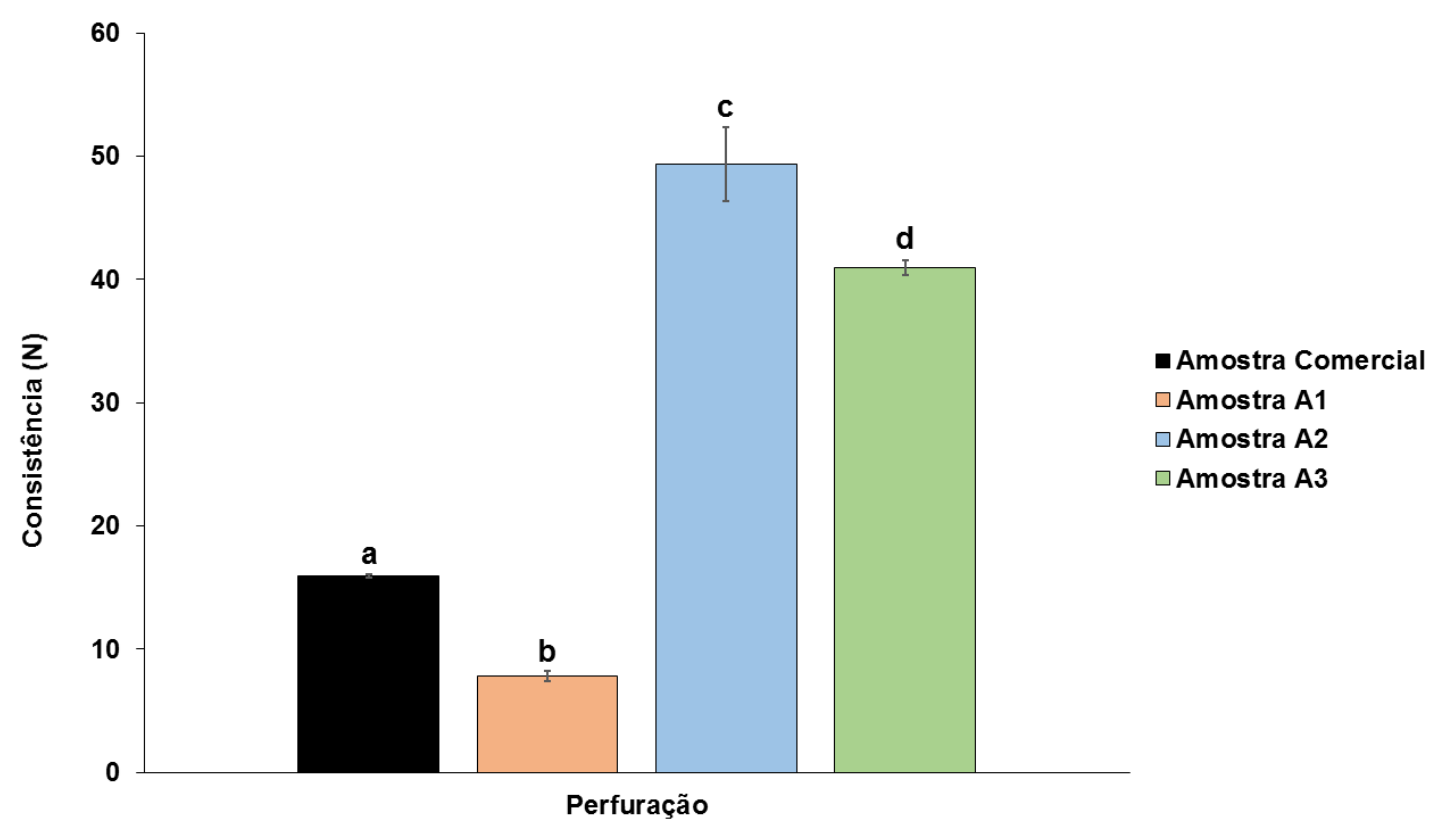

Figura 4: Propriedade de consistência das amostras de sabão artesanal. Letras iguais indicam que não há diferença estatística significativa entre as médias dos valores $(p>0,05)(n=3)$.

Fonte: De autoria própria.

A análise dos resultados apresentados na Figura 4 mostram que a amostra A1 obteve uma consistência de 7,78 $\pm 0,44 \mathrm{~N}$, esse valor está abaixo da consistência apresentada pela amostra comercial 15,89 $\pm 0,14 \mathrm{~N}$. Já em relação as amostras $A 2$ e A3, os valores de consistência obtidos estão acima da apresentada pela amostra comercial, sendo respectivamente, 49,33 $\pm 3,02$ $\mathrm{N}$ e 40,96 $\pm 0,62$. A análise estatística dos dados apresentou diferença significativa entre as médias das amostras $(p<0,05)$.

\section{Potencial hidrogeniônico $(p H)$}

A medida de $\mathrm{pH}$ é um parâmetro indicado para avaliar a estabilidade físico-química das amostras. As medições foram realizadas nos tempos de 10, 20 e 30 dias, afim de avaliar a estabilidade em função do tempo e da temperatura de armazenamento mantida à $25 \pm 2{ }^{\circ} \mathrm{C}$. Os resultados das medidas de pH para as amostras de sabão artesanal (A1, A2 e A3) e amostra comercial (comparativo) são apresentadas na Figura 5. 


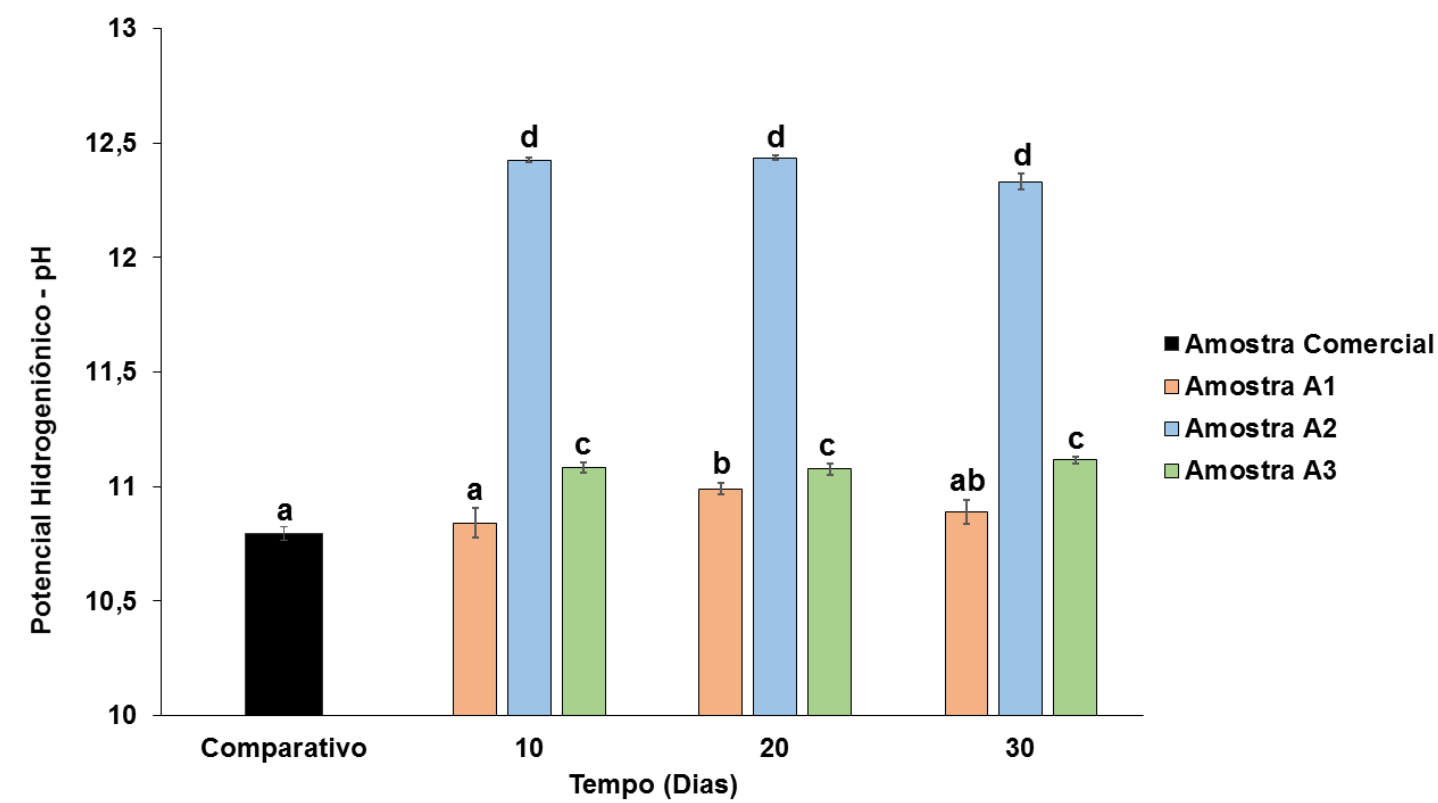

Figura 5: Medidas de $\mathrm{pH}$ das amostras de sabão artesanal. Letras iguais indicam que não há diferença estatística significativa entre as médias dos valores $(p>0,05)(n=3)$.

Fonte: De autoria própria.

Os resultados obtidos durante o período avaliado apresentaram medidas de $\mathrm{pH}$ entre 10,84 - 10,99 (A1), 12,33 - 12,43 (A2), 11,08 - 11,12 (A3) e 10,79 referente a amostra comercial. $A$ análise estatística dos dados não apresentou resultados significativos entre a amostra $A 1$ e amostra comercial $(p>0,05)$, já as demais amostras obtiveram medidas de $\mathrm{pH}$ com índice básico relativamente elevado $(p<0,05)$.

O monitoramento do $\mathrm{pH}$ é um fator indispensável, pois mesmo o sabão apresentando aspectos macroscópicos favoráveis, a soda cáustica utilizada na formulação requer um tempo para que seja totalmente consumida na reação de saponificação e dessa forma, estabilizando o pH. Esse período pós fabricação é denominado tempo de cura ou maturação, sendo citado na literatura técnico cientifica diferentes tempos de maturação, variando entre 7 dias (TESCAROLLO et al., 2015), 15 dias (TEIXEIRA et al., 2015) e 20 dias (FERREIRA J.; DOS SANTOS, 2016). Na produção artesanal do sabão, alguns fabricantes não possuem os equipamentos necessários para o monitoramento, podendo ocasionar um risco aos próprios fabricantes e aos consumidores do produto.

As medidas de $\mathrm{pH}$ de cada amostra mensuradas após o décimo dia não apresentaram diferença estatística significativa nos demais períodos avaliados $(p>0,05)$, constatando a estabilidade e término do tempo de maturação da soda cáustica, esse resultado está de acordo com estudo realizado por Santos et al. (2009) onde foi confirmado o tempo de maturação no décimo dia. No entanto, algumas amostras após estabilização do $\mathrm{pH}$ apresentaram índice básico elevado. Segundo Pereira et al. (2012) a utilização do sabão artesanal com medida de $\mathrm{pH}$ básico elevado pode causar danos nas mãos dos usuários, Revbea, São Paulo, V. 14, No 3: 50-74, 2019. 
devido a sua alcalinidade, atuando sobre a pele, removendo as camadas de gordura que protegem a epiderme, causando irritação local.

Conforme instruções técnicas sobre sabões elaborada por Uchimura (2007), é apresentado indicações para utilização em relação com a medida de pH apresentada: (i) entre 6,5 e 8,5 (próximo da neutralidade) é recomendado para a limpeza da pele e higiene pessoal; (ii) com pH próximo de 10 é recomendado para a limpeza de roupas; (iii) o pH que atingir 11,5 ou mesmo 12 é recomendado para a limpeza de utensílios domésticos, áreas comuns da casa ou até mesmo roupas e tecidos contaminados por fluídos corpóreos.

No entanto, discutindo sobre as informações apresentadas por Uchimura (2007), entendemos como faixa de neutralidade o pH de $7 \pm 0,5$ como ótimo para o uso na limpeza da pele. Já os sabões com pH próximo de 10 seriam indicados para a limpeza de roupas, utensílios domésticos e áreas comuns da casa. Por fim, sabões com medidas de $\mathrm{pH}$ que atingirem 11,5 ou mesmo 12 não são recomendados para o uso, devido alcalinidade elevada. De acordo com Agência Nacional de Vigilância Sanitária - Anvisa (2012) produtos com medidas de $\mathrm{pH}$ igual ou superior a 11,5 são considerados irritantes e corrosivos para pele, podendo ocasionar danos como ressecamentos, eritemas e dermatoses (BRASIL, 2012).

Dessa forma, as amostras A1 e A3 adquiridas e avaliadas se adequam melhor para a limpeza de roupas, utensílios domésticos e áreas comuns (pisos, bancadas, pias e vasos sanitários), no entanto, a amostra A2 não poderia ser utilizada, devido a medida de $\mathrm{pH}$ básico extremamente elevado.

Outro ponto constatado por meio dos resultados obtidos na análise de $\mathrm{pH}$, foi a correlação estabelecida com a propriedade de consistência apresentada por cada amostra, afirmando o relato apresentado por Silva e Santos (2016). Verificamos que as amostras cujo medidas de $\mathrm{pH}$ eram mais alcalinos, ou seja, indicativo de soda cáustica em excesso, também expressaram resultados de consistência superiores.

\section{Considerações Finais}

Os resultados obtidos por meio do estudo bibliográfico evidenciaram que o método contribuiu para ampliar a compreensão e apreensão dos dados, resultando em um referencial teórico-argumentativo sobre os impactos ambientais causados pelo descarte inadequado do óleo residual de cozinha. Paralelamente, o método proporcionou o contato com novos conceitos, observando práticas de ensino-aprendizagem ligadas ao tema por diversas áreas do conhecimento.

Essas informações adquiridas no referencial foram importantes para a discussão dos dados apreendidos pelo método etnográfico. Por meio desse método, foi possível reunir recortes sobre a trajetória cultural da fabricação do sabão artesanal produzido pelas mulheres no Munícipio de Paramirim, bem como, suas práticas de produção, as principais matérias-primas e 0 
direcionamento final do produto, sejam para utilização própria ou para comercialização. Observamos a necessidade de sensibilizar as fabricantes em relação a algumas questões, fornecendo maiores informações nas questões de segurança, principalmente para 0 uso de EPIs. No decorrer da observação/participante não foi evidenciado recortes direcionados aos impactos ambientais. No entanto, foram evidenciados recortes sobre outros eixos de tamanha importância, como aspecto social, educacional, político e o viés econômico.

O método etnográfico demostrou eficiência para apreensão dos dados no contexto observado. Além disso, os recortes obtidos proporcionaram discussões e reflexões, em relevância ao confrontar o conhecimento popular adquirido no cotidiano, com o conhecimento científico adquirido na literatura técnico-científica. Essas discussões possibilitaram reunir referências fundamentais sobre o tema evidenciado em outras localidades do território brasileiro.

O diálogo estabelecido com o conhecimento científico deixou evidente algumas precauções necessárias para a fabricação, o que nos impulsionou para a análise da qualidade do sabão. A análise sensorial das amostras evidenciou que A2 e A3 apresentaram separação de fases, indicando que a homogeneização durante 0 processo de fabricação não foi eficiente. Em relação a densidade, todas as amostras estão compatíveis com o comparativo. Os resultados de teor de umidade apresentaram um coeficiente de variância acima do estabelecido na norma, exceto para a amostra A1 (10 dias). De acordo com o teste de propriedade de consistência junto a análise de $\mathrm{pH}$, foi constatado que amostras com valores de consistência elevado é indicativo de excesso de soda cáustica no produto final.

A análise dos resultados obtidos em laboratório sugere que as amostras A1 e A3 estão adequadas para a limpeza de roupas, utensílios domésticos e áreas comuns, e consequentemente, aponta a produção de sabão como um destino viável para o reaproveitamento do óleo residual de cozinha.

Em somatória, os resultados do estudo fundamentam a fabricação de sabão como um potencial contexto para aplicação de uma proposta pedagógica de Educação Ambiental, exercida pelas próprias fabricantes. Para continuação da pesquisa será realizado o estudo de viabilidade econômica da fabricação do sabão, evidenciando a logística reversa e o empreendedorismo social para o gerenciamento adequado desse resíduo.

Visto que seu descarte inadequado causa impactos tanto no ambiente urbano quanto na natureza, resultando na poluição da água, solo e ar. A presença do óleo no ambiente aquático e terrestre criam condições capazes de causar a morte dos seres vivos, ocasionando desequilíbrio no ecossistema e refletindo na poluição atmosférica pela emissão de gás metano. Desta forma, a utilização do óleo residual de cozinha como matéria-prima para fabricação do sabão artesanal colabora para a retirada deste resíduo poluente do ambiente. 


\section{Referências}

ABNT, Associação Brasileira de Normas Técnicas. NBR 10.004. Resíduos Sólidos -Classificação, 2004.

ADOMILLI, G. K.; TEMPASS, M. C.; LOPES, R. DA C. Notas teóricometodológicas sobre a pesquisa etnográfica na área de Educação Ambiental. Revista Eletrônica do Mestrado em Educação Ambiental, v. 34, n. 3, p. 226-244, 2017.

AZEVEDO, O. D. A. et al. Fabricação de sabão a partir do óleo comestível residual: Conscientização e educação científica. XVIII Simpósio Nacional de Ensino de Física - SNEF, p. 1-9, 2009.

BERTÊ, M.; FANTINEL, L.; FERNANDES, L. DA S. Reaproveitamento de óleo de fritura para fabricação de sabão. Disciplinarum Scientia, v. 15, n. 2, p. 191-200, 2014.

BRASIL. Prefeitura Paramirim Amada Terra. Disponível em: $<$ https://www.paramirim.ba.gov.br/?page_id=40> Acesso em: 25 de jan. de 2019a.

BRASIL. Atlas do Desenvolvimento Humano no Brasil. Disponível em: $<$ http://www.atlasbrasil.org.br/2013/pt/perfil_m/paramirim_ba> Acesso em: 25 de jan. de 2019b.

BRASIL. NBR 13903 - ABNT - Associação Brasileira de Normas Técnicas, 1997.

BRASIL. Guia para Avaliação de Segurança de Produtos Cosméticos. Agência Nacional de Vigilância Sanitária - ANVISA. 2 ${ }^{a}$ edição, revista - Brasília (ANVISA), 2012.

BROCK, J. et al. Determinação experimental da viscosidade e condutividade térmica de óleos vegetais. Ciência e Tecnologia de Alimentos, v. 28, n. 3, p. 564-570, 2008.

CÉSAR, J.; PAOLI, M.-A.; ANDRADE, J. C. DE. A determinação da densidade de sólidos e líquidos. Chemkeys - Liberdade para aprender, p. 1-8, 2004.

DO MONTE, E. F. et al. Impacto ambiental causado pelo descarte de óleo; Estudo de caso da percepção dos moradores de Maranguape I, Paulista-PE. Revista Geama, v.1, n. 2, p. 205-219, 2015.

FERREIRA, J. R. DOS S.; DOS SANTOS, E. F. C. Recicler Brasil: Aplicando a Engenharia de Produção na reciclagem de óleo de fritura. XXXVI Encontro Nacional de Engenharia de Produção - ENEGEP, p. 1-9, 2016.

FERREIRA, M. C.; SANTOS, N. F. DOS. Ensino de química e pedagogia de projetos socioambientais: O reaproveitamento do óleo comestível na produção de sabão artesanal por alunos de uma escola do estado da Paraíba - O projeto limpando sua sujeira. IV Congresso Nacional de Educação - CONEDU, p. 110, 2014. 
FILHO, S. T. et al. Sistema de análise estequiométrica para produção de sabão a partir do óleo vegetal residual: Uma estratégia para redução do impacto ambiental. Revista Eletrônica em Gestão, Educação e Tecnolgia Ambiental, v. 15, n. 15, p. 3019-3025, 2013.

FREITAS, C. F.; BARATA, R. A. R.; NETO, L. S. M. Utilização do óleo de cozinha usado como fonte alternativa na produção de energia renovável, buscando reduzir os impactos ambientais. XXX Encontro Nacional de Engenharia de Produção - ENEGEP, São Carlos/SP, 2010.

HAMMERSLEY, M.; ATKINSON, P. Ethnography: Principles in practice. 3rd ed. United Kingdom: Routledge, p. 275, 2007.

LIMA, N. M. DE O. et al. Produção e caracterização de sabão ecológico - Uma alternativa para o desenvolvoimento sustentável do semiárido paraibano. Revista Saúde e Ciência On line, v. 3, n. 3, p. 26-36, 2014.

LISBOA, G. L. DA C. et al. Estudo de caso: Destinação do óleo vegetal usado em restaurantes e lanchonetes no bairro de Nazaré, em Belém-PA. II Congresso Amazônico de Meio Ambiente \& Energias Renováveis, p. 1-11, 2016.

LOPES, R. C.; BALDIN, N. Educação Ambiental para a reutilização do óleo de cozinha na produção de sabão - projeto "ECOLIMPO". IX Congresso Nacional De Educação - EDUCERE; III Encontro Sul Brasileiro de Psicopedagogia, p. 1035-1042, 2009.

MAGNANI, J.G.C. Etnografia como prática e experiência. Horizontes antropológicos, v. 15, n. 32, p. 129-156, 2009.

MATTA, L. D. M.; NETO, L. S. Ensino de Bioquímica e formação Docente: Propostas de projetos voltados para o Ensino Básico, desenvolvidos por estudantes de licenciatura. Química Nova na Escola - QNEsc, v. 38, n. 3, p. 224-229, 2016.

MILLIOLI, V. S. et al. Biorremediação de solo impactado com óleo cru: avaliação da potencialidade da utilização de surfatantes. Rio de Janeiro: CETEM/MCT (Série Tecnologia Ambiental), 2008.

MOTA JUNIOR, V. D. Educação Ambiental, Política, Cidadania e Consumo. Interacções, n. 11, p. 214-229, 2009.

MORGAN-MARTINS, M. I. et al. Reciclo-óleo: do óleo de cozinha ao sabão ecológico, um projeto de Educação Ambiental. Cinergis, v. 17, n. 4, p. 301306, 2016.

NEVES, E. O.; GUEDES, C. A. M.; SANTOS, K. C. DOS. Empreendedorismo social e sustentabilidade: Um estudo de caso sobre o projeto "mulheres em ação jogando limpo com a natureza" do IFNMG. Revista da FAE, v. 13, n. 2, p. 1-14, 2010.

OLIVEIRA, R. S. DE; DUTRA, J. M. Óleos residuais como tema de debate em Educação Ambiental. Scientia Amazonia, v. 5, n. 2, p. 92-95, 2016.

Revbea, São Paulo, V. 14, № 3: 50-74, 2019. 
OLIVEIRA, G. C. et al. Sustec jr nas escolas: Conscientização sobre a reciclagem do óleo comestível usado. Revista ELO-Diálogos em Extensão, v. 5, n. 1, 2016.

PEREIRA, C. S. D. S. et al. Acão social e ambiental na comunidade de Engenheiro Gutierrez - IRATI/PR com o uso de materiais recicláveis. Revista PublicAção, v. 3, n. 1, p. 23-31, 2012.

PITTA JUNIOR, O. S. R. et al. Reciclagem do óleo de cozinha usado: uma contribuição para aumentar a produtividade do processo. In: Internacional Workshop Advances in Cleaner Production. p. 1-10, 2009.

PRAIA, J.; CACHAPUZ, A.; GIL-PÉREZ, D. A hipótese e a experiência científica em educação em ciência: Contributos para uma reorientação epistemológica. Ciência \& Educação, Bauru, v. 8, n. 2, p. 253-262, 2002.

RABELO, R. A.; FERREIRA, O. M. Coleta seletiva de óleo residual de fritura para aproveitamento industrial. Universidade Católica de Goiás, v. 6, p. 1-21, 2008.

RAMALHO, H. F.; SUAREZ, P. A. Z. A Química dos óleos e gorduras e seus processos de extração e refino. Revista Virtual de Química - RVq, v. 5, n. 1, p. 2-15, 2013.

REIGOTA, M. O que é Educação Ambiental. 2. Ed. São Paulo: Editora Brasiliense, 2009.

REIS, V.; LUNARDI-MENDES, G. M. O registro do etnógrafo: Reflexões sobre a prática etnográfica educacional. Revista Contemporânea de Educação, v. 13, n. 26, p. 164-183, 2018.

RODRIGUES, L. B.; COUTINHO, J. P.; SILVA, C. A. DA. Proposta de reaproveitamento do óleo de fritura residual em um restaurante industrial. RGSA - Revista de Gestão Social e Ambiental, v. 4, n. 3, p. 136-145, 2010.

SANTOS FILHO, R. C. Dos. et al. O aproveitamento de resíduos sólidos urbanos, por meio do processo de compostagem aeróbia enriquecida com casca de sururu para aproveitamento na construção civil. Caderno de Graduação-Ciências Exatas e Tecnológicas-UNITALAGOAS, v. 4, n. 2, p. 125, 2017.

SANTOS, D. M.; NAGASHIMA, L. A. Saber popular e o conhecimento científico: Relato de experiência envolvendo a fabricação de sabão caseiro. REnCiMa, v. 8, n. 2, p. 127-142, 2017.

SANTOS, V. M. L. DOS et al. Preservação ambiental e reciclagem de óleos residuais. Extensão em Foco, n. 3, p. 99-107, 2009.

SCHOTT FILHO, O. et al. Projeto Estiva: Uma iniciativa de gestão de resíduos sólidos urbanos em comunidades de baixa renda. Revista ELO-Diálogos em Extensão, v. 6, n. 3, 2017. 
SILVA, Â. J. DA; SANTOS, W. L. P. Conhecimento popular e a Educação CTS em oficinas de sabão caseiro. Indagatio Didactica, v. 8, n. 1, p. 1931-1946, 2016.

SILVA, L. N. A.; BRAZ, C. O.; PINHEIRO, A. S. F. Confecção de sabão caseiro a partir do reaproveitamento do óleo de cozinha como ferramenta de Educação Ambiental em escolas de Santarém-Pará. VII Congresso Brasileiro de Gestão Ambiental-ConGeA, Campo Grande/MS, 2017.

SIQUEIRA, M. M.; MORAES, M. S. Saúde coletiva, resíduos sólidos urbanos e os catadores de lixo. Ciência \& Saúde Coletiva, v. 14, n. 6, p. 2115-2122, 2009

TEIXEIRA, C. R. et al. Abordagem CTSA - Prática pedagógica no Ensino de Ciências a partir da produção de sabão caseiro. Pedagogia em Foco, v. 10, n. 3, p. 41-53, 2015.

TESCAROLLO, I. L. et al. Proposta para avaliação da qualidade de sabão ecológico produzido a partir do óleo vegetal residual. Revista Eletrônica em Gestão, Educação e Tecnolgia Ambiental, v. 19, n. 3, p. 871-880, 2015.

TOMASI, K. et al. Perfil de consumo e descarte de óleo comestível no município de ijuí-rs. Revista Contexto \& Saúde, v. 14, n. 27, p. 54-64, 2014.

UCHIMURA, M. S. Dossiê Técnico - Sabão. Instituto de Tecnologia do Paraná, p. 1-27, 2007.

WEBER, F. A Entrevista, a Pesquisa e o Íntimo, ou: Por que censurar seu diário de campo? Horizontes Antropológicos, v. 15, n. 32, p. 157-170, 2009.

WILDNER, L. B. A.; HILLIG, C. Reciclagem de óleo comestível e fabricação de sabão como instrumento de Educação Ambiental. Revista Eletrônica em Gestão, Educação e Tecnolgia Ambiental, v. 5, n. 5, p. 813-824, 2012. 